\title{
Comparative study of power smoothing techniques produced by a wind energy conversion system
}

\author{
Hind Elaimani \\ Mohammed V University in Rabat, Ecole Nationale \\ Supérieure d'Arts et Métiers (ENSAM), Research Center \\ of Engineering and Health Sciences and Technologies \\ (STIS) Avenue de l'Armée Royale, Rabat, Morocco. \\ h.elaimani@gmail.com \\ ID: https://orcid.org/0000-0002-6075-2883

\section{Noureddine ELmouhi} \\ Mohammed V University in Rabat, Ecole Nationale \\ Supérieure d'Arts et Métiers (ENSAM), Research Center \\ of Engineering and Health Sciences and Technologies \\ (STIS) Avenue de l'Armée Royale, Rabat, Morocco. \\ n.elmouhi@gmail.com \\ ID : https://orcid.org/0000-0002-3379-7568
}

\begin{abstract}
Ahmed Essadki
Mohammed V University in Rabat, Ecole Nationale Supérieure d'Arts et Métiers (ENSAM), Research Center of Engineering and Health Sciences and Technologies (STIS) Avenue de l'Armée Royale, Rabat, Morocco. ahmed.essadki1@gmail.com
\end{abstract}

\author{
Rachid Chakib \\ Laboratory of Innovation in Management and \\ Engineering for Enterprise (LIMIE), ISGA Rabat Institut \\ supérieur d'ingénierie et des affaires, 27 Avenue Oqba, \\ Agdal, Rabat, Morocco. \\ rachid.chakib@isga.ma
}

\begin{abstract}
This paper aims to present and compare two techniques used to smooth the injected power in the grid from a doublyfed induction generator (DFIG) based conversion system. The first technique based on an inertial storage system while the second is founded on limiting the power captured by the wind turbine. The overall system composed of a wind energy conversion system (WECS) allowing to convert a wind power into electric power. It is controlled by two converters, grid side converter and a rotor side converter, both are controlled by sliding mode. The storage system is used to consume power which exceeds the setpoint due to storing it or producing more in the event of a lack, the system is controlled through the flywheel side converter by the sliding mode. Numerical simulations were carried out using Matlab/Simulink software.
\end{abstract}

Keywords: DFIG modelling, Power smoothing, Sliding mode, Wind Energy

\section{INTRODUCTION}

In recent years, the need for electricity has continued to increase. Research projects have focused on clean and inexhaustible sources of energy, of which renewable energy is part. More precisely and thanks to its advantages, researchers have turned to wind energy.

Different structure of wind energy conversion system exists, the most used one is based on DFIG. It has emerged as one of the most economical and efficient solutions for the electrical energy generation. It is composed of a doubly-fed induction generator DFIG, with a direct connection of the stator to the grid, connection of its wound rotor through two power converters [1]. The first converter is the RSC (Rotor Side Converter) it controls the DFIG's active and reactive power, the second GSC (Grid Side Converter) it controls the DC link's voltage. Several researches have been carried out on the control of these power converters in order to properly control the generated power.
Different techniques exist to control the converters such as the PI regulators, the Backstepping technique, the direct power control, the Active Disturbance Rejection Control (ADRC), the direct torque control and the control by sliding mode, which will be used in this work. These techniques are not efficient against the wind fluctuation, it remains an inevitable and direct threat. in fact, the wind fluctuations appear at the level of the produced power, therefore we see that the power produced does not follow its reference, when the wind speed decreases, we produce less than what is required, when it is the reverse, we produce more than we need.

To remedy this problem, it is necessary to act either before the conversion on the mechanical part by reducing the blades' rotational speed acting on their orientation, or after the conversion by using the storage of energy technique [2]. In the mechanical part, we act on the blades' orientation angle to reduce the speed of the wind turbine and subsequently reduce or even limit the electrical produced power, by using the blades 
orientation system. An ESS (energy storage system) contributes to the energy balance between production and need. It provides energy when needed and stores it at high wind speeds where energy demand is reduced, this balance generates a smooth power which respects its reference.

Indeed, there are several techniques of energy storage, such as storage by hydraulic pumping of energy, storage in the form of potential energy from compressed air, storage in the form of chemical energy and storage of kinetic energy in a spinning mass also called a flywheel. All these methods are widely studied in [3],the flywheel technique is further developed in $[3,4,5,6]$.

Energy capacity, self-discharge, environmental reliability and potential are the main factors in the choice of an energy storage system, according to the comparative study carried out in [7] therefore and according to its comparison's results, the ESS using flywheel are favorably proposed.

Many works have focused on the regulation of the produced power which depends on the converted power (at the DFIG's output) and the power of the ESS. Different control laws have been developed to ensure the balance between the supplied power and the stored power from or in the ESS.

In [6] the flywheel energy storage system consists of an electronic power converter supplying a squirrelcage induction machine coupled to a flywheel. The squirrel cage machine is controlled through its flux, the latter is calculated using the flux weakening algorithm. The control is provided by a traditional linear proportional-integral $(\mathrm{PI})$ controller. The same regulators are used in [2], [8] in addition to a fuzzy logic-based supervisor to compute the regulated power value. However, taking into account the system parameters' variation (due, especially to modelling uncertainties and some physical phenomena), other control laws have been proposed as in [4] the author used the same structure in $[2],[8]$ but with a control based on the backstepping technique.

Most of the works cited above are concerned with the power smoothing using an ESS by controlling either the flux or the torque, subsequently a supervision block based on fuzzy logic to control the power. In this paper we tried to directly control the ESS by using the sliding mode technique to try to achieve higher performances. we compared this new approach with the technique using the blades orientation system limiting the pitch angle of the blades known as pitch control, to see the advantages and disadvantages of both of techniques.

This paper is structured as follows: After the introduction, the second part presents the topology of the system studied including the modelling of the turbine, the doubly fed induction generator, the power converters, the filter, the control part using the sliding mode tech- niques. Then the smoothing power techniques are shown in the third section. The last section is dedicated to the simulation results, carried out using the Matlab/ Simulink software, followed by a conclusion.

\section{THE TOPOLOGY OF THE SYSTEM}

The most suitable topology of the wind energy conversion system is the one based on the DFIG, which is directly connected to the grid from the stator, connected to the grid through two power converters from the wound rotor, a DC link placed among the converters as shown in figure 1.

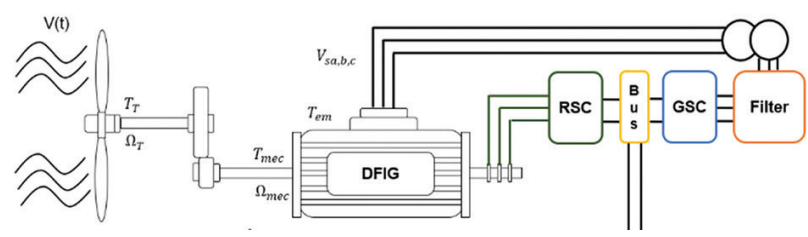

Fig.1. Block diagram of the wind energy converter system

\subsection{THE MODELLING PARTS}

\subsubsection{The turbine modelling}

The source of the wind energy conversion system is the kinetic energy of the wind. The latter is equivalent to an air mass displacement field characterized by a variable speed and a random trajectory applied to the turbine. It creates forces on the surfaces of its blades, which generates a rotational movement of the latter. It is an aerodynamic conversion.

The aerodynamic power expression is given by:

$$
P_{a \mathrm{e} r}=\frac{1}{2} \rho S V^{3}
$$

According to betz's theory the turbine power Pt is given by:

$$
P_{T}=P_{a \mathrm{é} r} C_{p}(\beta, \lambda)
$$

$C_{p}$ is a specific coefficient to each wind turbine.

The turbine torque is defined by:

$$
T_{T}=\frac{P_{T}}{\Omega_{T}}
$$

the gearbox is a speed adapter from that of the turbine to that of the generator. Its gain is given by:

$$
G=\frac{T_{T}}{T_{m e c}}=\frac{\Omega_{m e c}}{\Omega_{T}}
$$

Applying the fundamental relation of the dynamics, the generator tree is modeled by the following equation:

$$
J \frac{d \Omega_{m e c}}{d t}=\sum T=T_{m e c}-T_{e m}-T_{v i s}
$$

From the equations given above, we conclude the block diagram of the turbine given by figure 2 . 


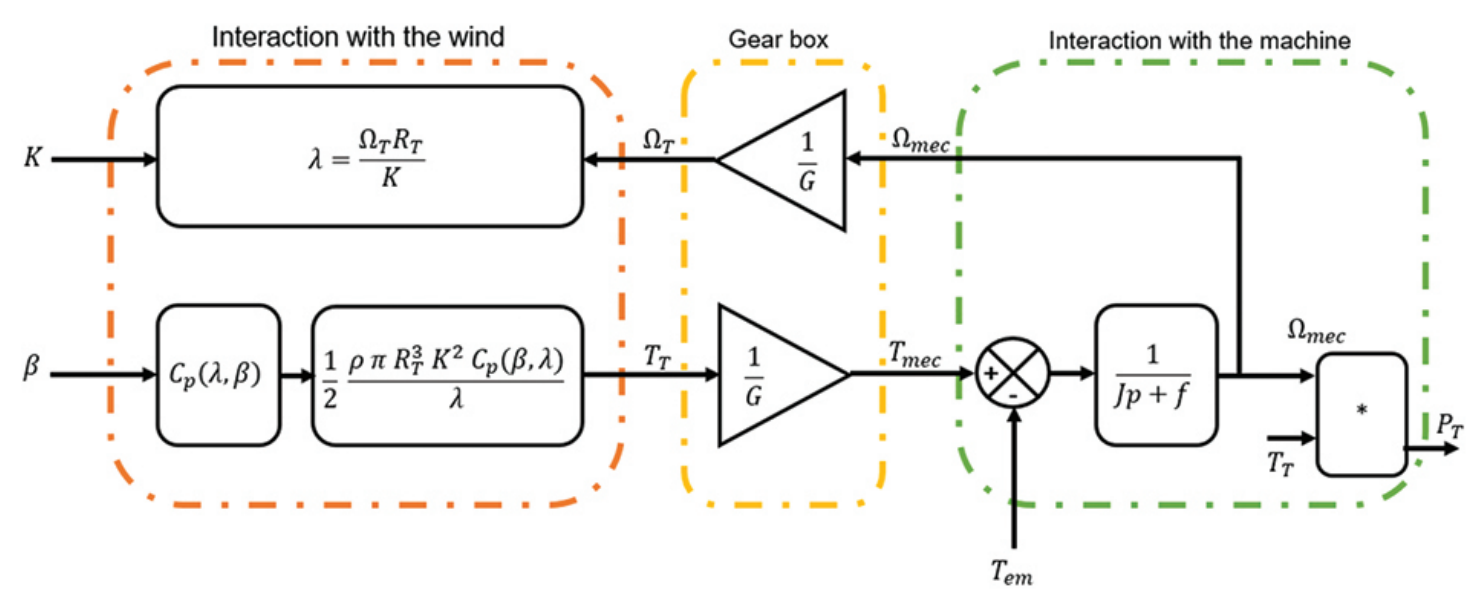

Fig. 2. Block diagram of the turbine

\subsubsection{THE DFIG modelling}

The electrical part modelling is needed after the modelling of the mechanical part, the first element to model is the DFIG.

Starting from the schematic representation of a DFIG in the three-phase reference widely presented in $[9,10,11]$ and by adopting the hypothesis of a stator resistance Rs as negligible (given the power of the DFIG), the stator flux $\varphi s$ is constant (while Vs is constant) and oriented along the axis $d[12,13,14]$ the machine's new equations are given by:

$$
\left\{\begin{aligned}
V_{s d}= & 0 \\
& V_{s q}=V_{s}=\omega_{s} \varphi_{s} \\
V_{r d}= & R_{r} I_{r d}+\frac{d \varphi_{r d}}{d t}-\omega_{r} \varphi_{r q} \\
V_{r q}= & R_{r} I_{r q}+\frac{d \varphi_{r q}}{d t}+\omega_{r} \varphi_{r d}
\end{aligned}\right.
$$

$$
\begin{aligned}
& \text { And } \\
& \left\{\begin{array}{c}
\varphi_{s d}=\varphi_{s}=L_{s} I_{s d}+M I_{r d} \\
0=L_{s} I_{s q}+M I_{r q} \\
\varphi_{r d}=L_{r} I_{r d}+M I_{s d} \\
\varphi_{r q}=L_{r} I_{r q}+M I_{s q}
\end{array}\right.
\end{aligned}
$$

The stator currents are given by the following system:

$$
\left\{\begin{array}{c}
I_{s d}=\frac{\varphi_{s}}{L_{s}}-\frac{M}{L_{s}} I_{r d} \\
I_{s q}=-\frac{M}{L_{s}} I_{r q}
\end{array}\right.
$$

The active and reactive powers become:

$$
\left\{\begin{array}{c}
P_{S}=V_{s q} I_{s q}=-\frac{M}{L_{s}} V_{s} I_{r q} \\
Q_{s}=V_{s q} I_{s d}=\frac{V_{s} \varphi_{s}}{L_{s}}-\frac{M V_{s}}{L_{s}} I_{r d}
\end{array}\right.
$$

by injecting the expression of the stator currents given by equation 9 , into the equations of the rotor fluxes, we obtain:

$$
\left\{\begin{array}{c}
\varphi_{r d}=\left(L_{r}-\frac{M}{L_{s}}\right) I_{r d}+\frac{M \varphi_{s}}{L_{s}}=\left(L_{r}-\frac{M^{2}}{L_{s}}\right) I_{r d}+\frac{M V_{s}}{\omega_{s} L_{s}} \\
\varphi_{r q}=\left(L_{r}-\frac{M^{2}}{L_{s}}\right) I_{r q}
\end{array}\right.
$$

By injecting (10) into (6) a new system of direct and quadrature rotor voltages is obtained:

$$
\begin{array}{r}
V_{r d}=R_{r} I_{r d}+\left(L_{r}-\frac{M^{2}}{L_{s}}\right) \frac{d I_{r d}}{d t}-g \omega_{s}\left(L_{r}-\frac{M^{2}}{L_{s}}\right) I_{r q} \\
V_{r q}=R_{r} I_{r q}+\left(L_{r}-\frac{M^{2}}{L_{s}}\right) \frac{d I_{r q}}{d t}+g \omega_{s}\left(L_{r}-\frac{M^{2}}{L_{s}}\right) I_{r d}+g
\end{array}
$$

\subsubsection{The power converters and filter modelling}

The DFIG's output is connected to the grid trough two power converter as shown in the figure 1.

The simple voltages given at the output of the converter are $[15,16,17]$

$$
\left(\begin{array}{l}
V_{a} \\
V_{b} \\
V_{c}
\end{array}\right)=\frac{E}{6}\left(\begin{array}{ccc}
2 & -1 & -1 \\
-1 & 2 & -1 \\
-1 & -1 & 2
\end{array}\right)\left(\begin{array}{l}
S_{1} \\
S_{2} \\
S_{3}
\end{array}\right)
$$

\subsubsection{The DC link modelling}

It consists of a capacitor $C$ placed between the converters. It is governed by the following electrical equation:

$$
\frac{d U_{d c}}{d t}=\frac{1}{C}\left(I_{G S C}-I_{R S C}\right)
$$

\subsubsection{The filter modelling}

The filter is composed of a resistor $\mathrm{R}$ in series with an inductance $L$ called respectively the total resistance and inductance of the line.

The line voltages are given by:

$$
\left\{\begin{array}{l}
V_{t 1}=R I_{t 1}+L \frac{d I_{t 1}}{d t}+V_{a} \\
V_{t 2}=R I_{t 2}+L \frac{d I_{t 2}}{d t}+V_{b} \\
V_{t 3}=R I_{t 3}+L \frac{d I_{t 3}}{d t}+V_{c}
\end{array}\right.
$$

\subsection{THE CONTROL PART}

\section{- The RSC's and FSC's Control}

Different control techniques exist, control using PI correctors remains the most basic, backstepping and sliding mode are more efficient in terms of the produced energy quality. 
The purpose of this paragraph is to synthesize a control law based on the sliding mode technique applied to the rotor and flywheel side converter to control the active and reactive powers generated by the DFIG at the desired values. This technique is detailed in $[1,18,20]$.

The model of the DFIG's control used is the oriented stator flux, the electrical quantities which are all expressed in a fixed reference frame linked to the stator. $(d, q)$. eq $(6,7,8,9)$.

The powers' control is equivalent to the rotor currents' control, so we deduce the following rotor currents expressions.

$$
\begin{gathered}
I_{r q}=-\frac{L_{s}}{M V_{s}} P \\
I_{r d}=-\frac{L_{s}}{M V_{s}} Q+\frac{V_{s}}{\omega_{s} M}
\end{gathered}
$$

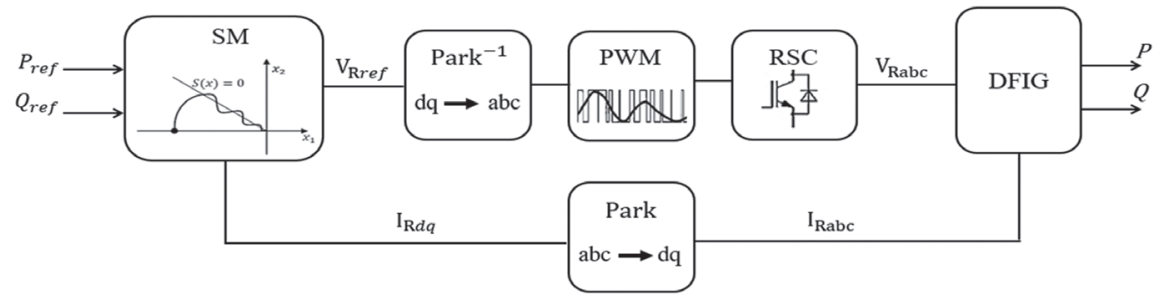

Fig. 3. Principal block diagram of the sliding mode control

The block diagram of the control used is illustrated in figure 3 , it is a control of the active and reactive power through the rotor currents, by actuating the rotor voltages, therefore the elaboration of the control law results by determining the expression of the reference voltages of the PWM block which controls the converter connected to the rotor of the DFIG.

\subsubsection{The Switching Surface Choice}

The slinding mode technique uses a switching surface on which the control will slide.

The switching surface's expression is as follows:

$$
\begin{aligned}
& s(P)=I_{r q}^{r e f}-I_{r q} \\
& s(Q)=I_{r d}^{r e f}-I_{r d}
\end{aligned}
$$

From equation 15 we can define

$$
\begin{gathered}
I_{r q}{ }^{r e f}=-\frac{L_{s}}{M V_{s}} P^{r e f} \\
I_{r d}^{r e f}=-\frac{L_{s}}{M V_{s}} Q^{r e f}+\frac{V_{s}}{\omega_{s} M}
\end{gathered}
$$

\subsubsection{Calculation of the vector's control}

The vector's control is given by the rotor voltages as shown in figure 3 . The sliding mode is performed provided that the Lyaponov attractiveness relation is less than zero, so the surfaces' devatives are given by:

$$
\begin{aligned}
& \dot{s}(P)=\dot{I}_{r q}^{r e f}-\dot{I}_{r q} \\
& \dot{s}(Q)=\dot{I}_{r d}^{r e f}-\dot{I}_{r d}
\end{aligned}
$$

By replacing the currents derivatives of the equation 18 by their expressions (equation: 11) we have:

$$
\dot{s}(P)=\left(\begin{array}{c}
L_{s} \\
M V_{s} \\
\dot{P}
\end{array}\right.
$$

The sliding command used is given by the sign function, as specified in the following equation:

$$
\begin{gathered}
\dot{s}(P)=-v_{1} \operatorname{sing}(s(P)) \\
V_{r q}=-\frac{L_{s} \sigma L_{r}}{M V_{s}} \dot{P}^{r e f}+R_{r} I_{r q}+ \\
g w_{s} L_{r} \sigma I_{r d}+g \frac{M V_{s}}{L_{s}}+L_{r} \sigma v_{1} \operatorname{sgn}((s(P)) \\
V_{r q_{e q}}=-\frac{L_{s} \sigma L_{r}}{M V_{s}} \dot{P}^{r e f}+R_{r} I_{r q}+g w_{s} L_{r} \sigma I_{r d}+g \frac{M V_{s}}{L_{s}} \\
V_{r q_{c o m}}=L_{r} \sigma v_{1} \operatorname{sgn}((s(P)))
\end{gathered}
$$

we have to redo the same calculation to find the control vector of the reactive power.

$$
\begin{gathered}
V_{r d_{e q}}=L_{r} \sigma\left(-\frac{L_{s}}{M V_{s}} \dot{Q}^{r e f}+\frac{V_{s}}{M w_{s}}\right)+R_{r} I_{r d}-g w_{s} L_{r} \sigma I_{r q} \\
V_{r d_{c o m}}=L_{r} \sigma v_{2} \operatorname{sgn}(s(Q))
\end{gathered}
$$

$v_{1}$ and $v_{2}$ are constants determined using the genetic algorithm in order to have the closest response to its reference.

The sliding mode block illustrated by figure 4 is detailed in figure 5 .

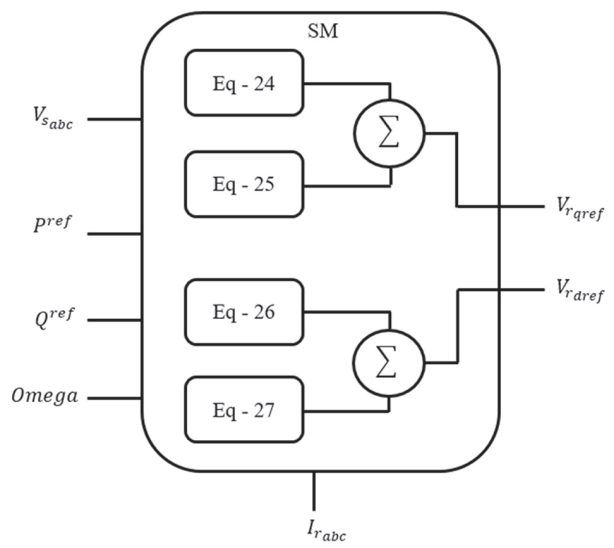

Fig. 4. Vector's control block diagram of the sliding mode 


\subsubsection{The GSC's control}

The purpose of the grid side converter's control is to control two large quantities; therefore, the control can be divided into two parts:

Controlling the grid side converter consists in:

- Regulating the DC bus voltage to follow its reference.

- Keeping the reactive power's reference to zero to ensure a unit power factor.

In fact, in the same way and using the equations 13 and 14 , we elaborate a control law based on the SM to control the GSC.

\section{THE ACTIVE POWER SMOOTHING TECHNIQUES}

The active power smoothing techniques discussed in this paper are: the use of an ESS and the blades orientation system. The first one consists on storing the active power in case of excess or recovering it if necessary. The second one limits power only in case of excess.

\subsection{FLYWHEEL ENERGY STORAGE SYSTEM}

Storing electrical energy involves converting it into another form and then storing it|[21,22,23]. The inertial energy storage system is based on a dual power machine that converts electrical power into inertial power which is then stored in a flywheel as shown in the figure 5 .

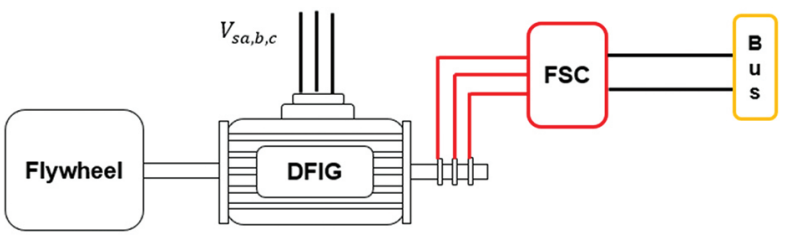

Fig.5. Block diagram of the flywheel energy storage system

Wind turbines are considered as negative loads for the electrical grid, because they do not consume electrical energy so the active power produced by the overall system is negative, its expression is given by:

$$
P_{\text {grid }}=P_{D F I G}+P_{E S S}
$$

The $P_{D F I G}$ is the power of the wind converted by the DFIG into electrical power, it presents several fluctuations because of the source. $P_{E S S}$ is the power of the storage system, the exchange of this power is done in both directions, towards the storage system in the event that there are losses of the produced power in relation to the setpoint (we speak of load of the flywheel, or from the storage system in the event of a need to reach the setpoint (discharge of the flywheel) as shown in the figure 6.

The ESS active power's expression is given by:

$$
\begin{aligned}
& P_{E S S}=P_{\text {grid }_{\text {ref }}}-P_{D F I G} \\
& E_{E S S}=E_{E S S 0}+\int P_{E S S} d t
\end{aligned}
$$

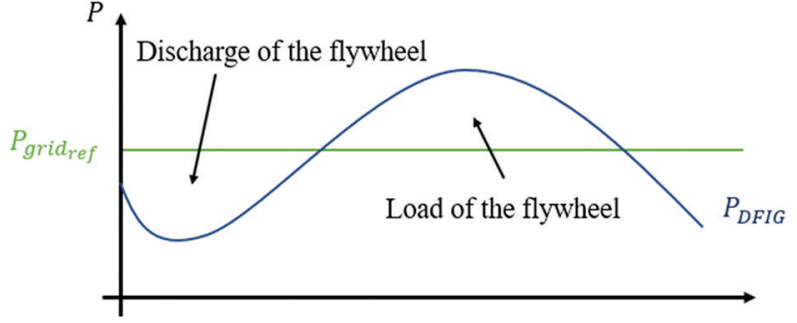

Fig. 6. charge and discharge

of the flywheel depending on the produced power and the desired power

The literature has proposed several configurations of the FESS $[24,25,26,27,28]$. In this paper, the electric motor used to drive the flywheel is a DFIG. The energy stored in a flywheel is expressed by:

$$
\begin{gathered}
E_{E S S}=0.5 \cdot J_{E S S} \cdot \Omega_{E S S}^{2} \\
\Omega_{E S S}=\sqrt{\frac{2 \cdot E_{E S S}}{J_{E S S}}}
\end{gathered}
$$

\subsection{THE BLADES' ORIENTATION SYSTEM}

It is a system which acts on the pitch angle of the blades to a reference value $\beta_{\text {ref }}$ desired, this angle's choice generally used to adjust the speed of the turbine and the mechanical power generated. adjusting blades, the turbine's performances are modified more precisely the power coefficient. The blades are facing the wind at low wind speed and tilt for high wind speeds to reduce the power coefficient [9]. Generally, the blade orientation system is approximated by a transfer function of $1 \mathrm{st}$ order with a time constant $T_{\beta}$.

The aim is to limit and maintain the produced power at its nominal value $P_{\text {nom }}$ in order to preserve all the elements of the conversion chain around this power. The pitch control makes it possible to reduce the power coefficient and thus limit thus the converted power afterwards the produced one [29,30].

To obtain the reference angle $\beta_{\text {ref }}$ we correct the generated power $P_{T}$ to its reference $P_{\text {ref }}$ using a PI regulator.

The whole blades' orientation system is shown in figure 7.

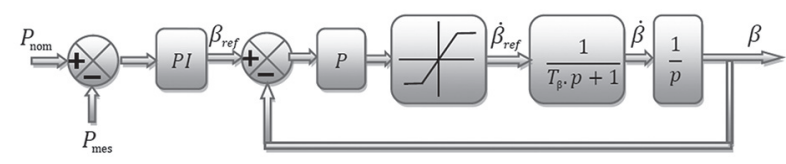

Fig. 7. The block diagram of the pitch control

\section{THE SIMULATION RESULTS}

The simulation studies are carried out with the characteristics of the system presented in the appendix. All the simulations are run with the same wind profile with an average speed of $8 \mathrm{~m} / \mathrm{s}$ for a duration of $50 \mathrm{~s}$, as shown in figure 8. 
The figure 9 shows the stator voltage, which is a balanced three-phase system of frequency $50 \mathrm{~Hz}$ and effective value $400 \mathrm{~V}$.

For this first part of simulation, we present the results of the solution based on the use of an ESS. Figure 12 shows the produced electric power P_DFIG which has the same form of fluctuations present in the wind, since in the equation 1 the power captured by the turbine is proportional to the cube of the wind. And always in the same figure, we have the reference power $P_{\text {gridref }}$

The utility of the ESS is to provide power when needed or to store it in case of excess, as shown in figure 13. From 8 to $9 \mathrm{~s}$ the produced power $P_{D F I G}$ is less than the desired power $P_{\text {gridref }}$. The ESS produced the difference power, in the interval $[9 \mathrm{~s}, 10 \mathrm{~s}] P_{D F I G}$ is greater than the power $P_{\text {gridref }}$. The difference is stored as kinetic energy, as shown in figure 14, clearly sees between 8 and $9 \mathrm{~s}$ that the kinetic energy increases following the loading of the flywheel.

The total active power injected into the grid faithfully follows its reference $P_{\text {gridref }}$ except a very small oscillations as shown in figure 15, while the one using the pitch control technique presents some important fluctuations as shown in figure 18. More precisely, the pitch control technique limits the power so as not to exceed its reference, if on the other hand the power is lower than its reference, it unchanged. So, this technique keeps the power fluctuations lower than the reference and eliminates the higher ones.

In figure 19 we can see the two powers injected into the grid using the two techniques explained previously, the goal is to follow $P_{\text {gridref }}$ Note that the pitch control technique is less efficient compared to the use of the ESS, power $P_{E S S}$ which is well smoothed.

Figures 10 and 16 show the stator's currents. Comparing the two, we notice that the technique using the ESS gives a current which reaches very large values, unlike the current of the second technique which remains limited. The same observation for the rotor's currents shown in figure 11 and 17.

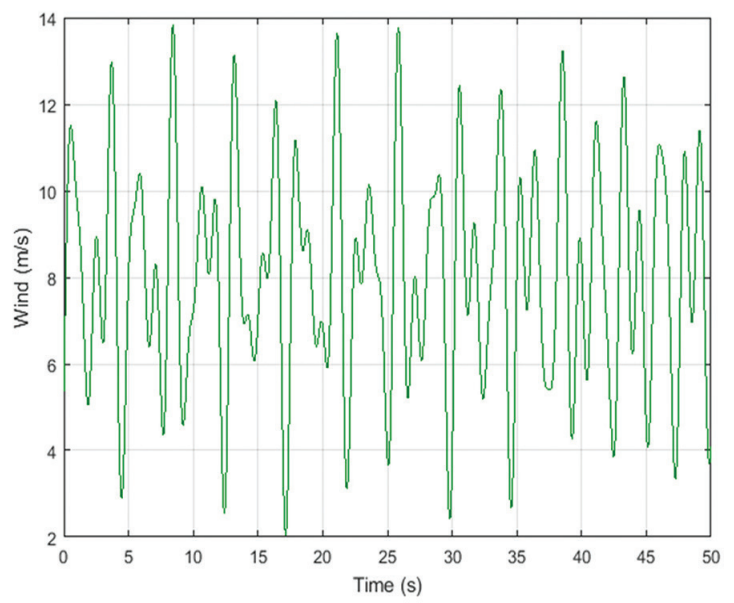

Fig. 8. The wind profile

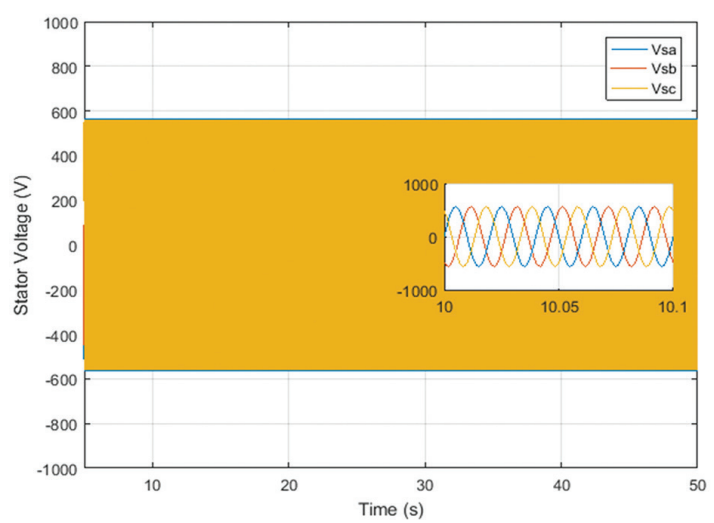

Fig. 9. The stator's Voltages

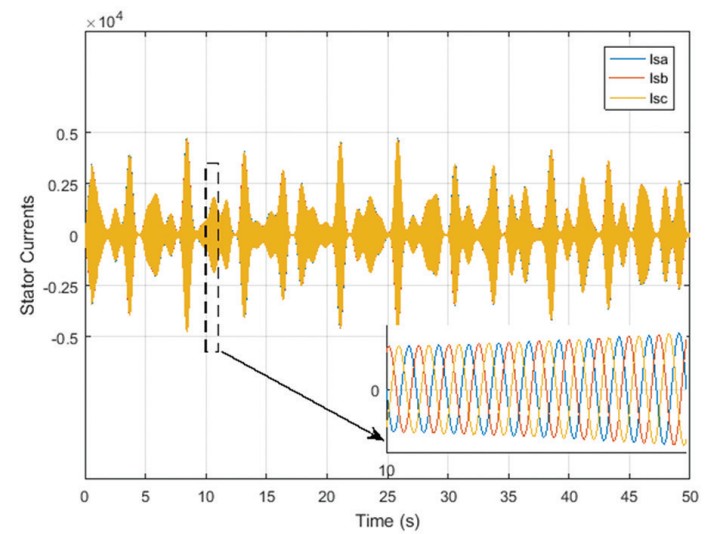

Fig. 10. The stator's currents using the ESS

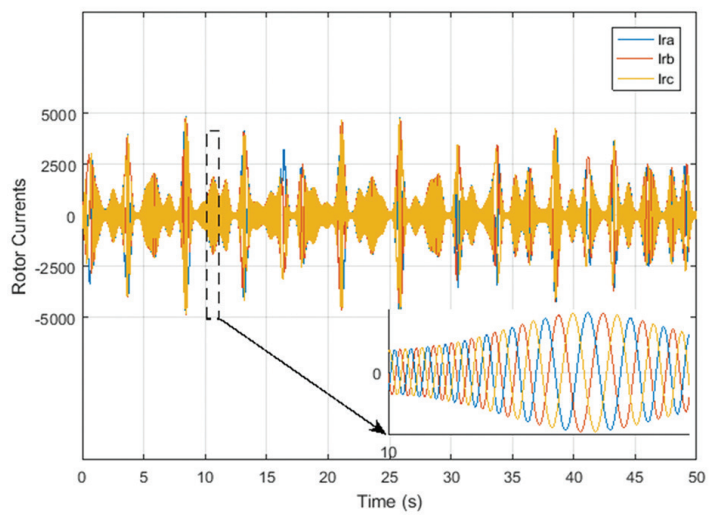

Fig. 11. The rotor's currents using the ESS

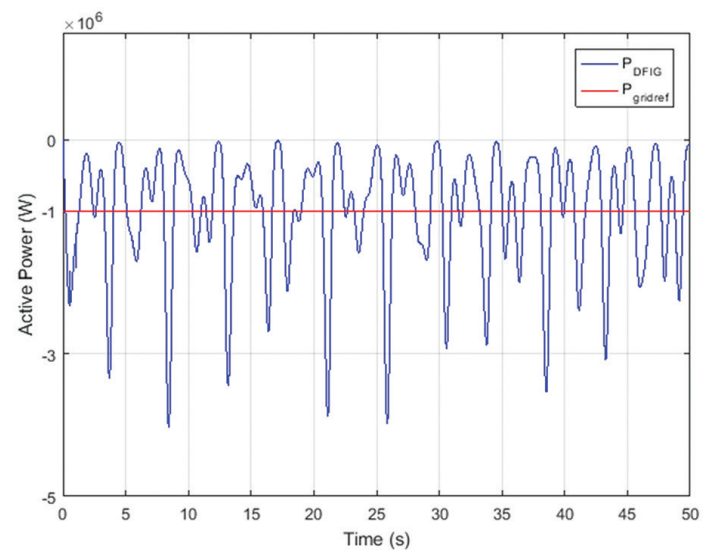

Fig. 12. The DFIG's active power with the grid reference one 


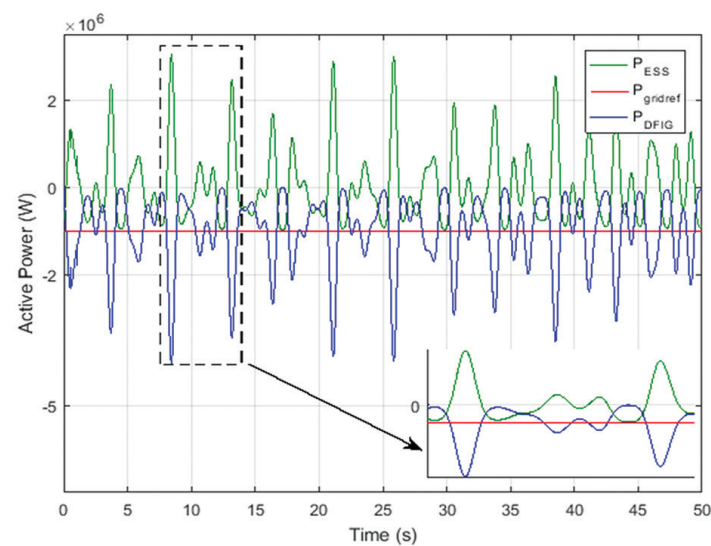

Fig. 13. The ESS's active power

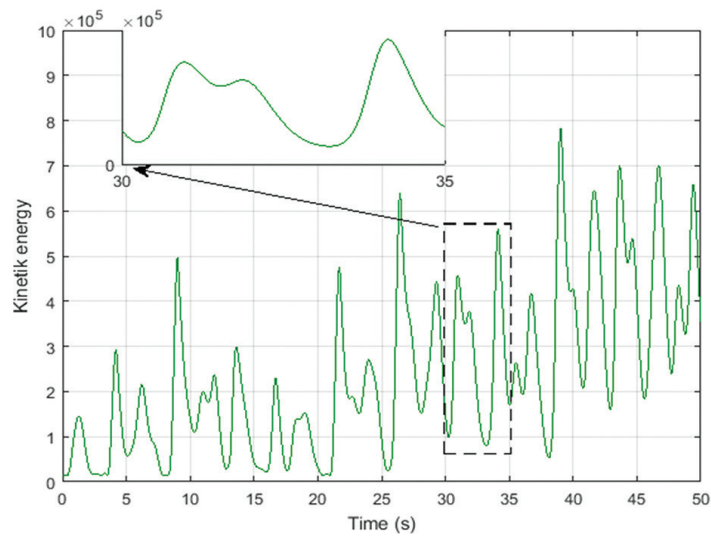

Fig. 14. The flywheel's Kinetik energy

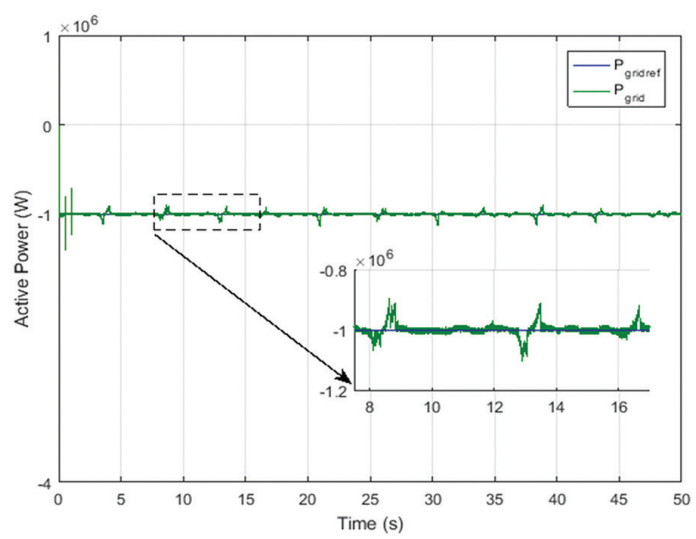

Fig. 15. The active power injected in the grid and its reference using the ESS

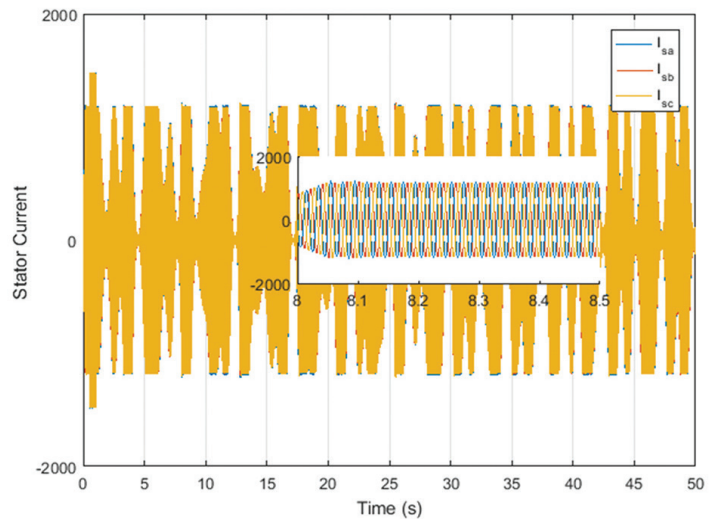

Fig. 16. The stator's current using the pitch control

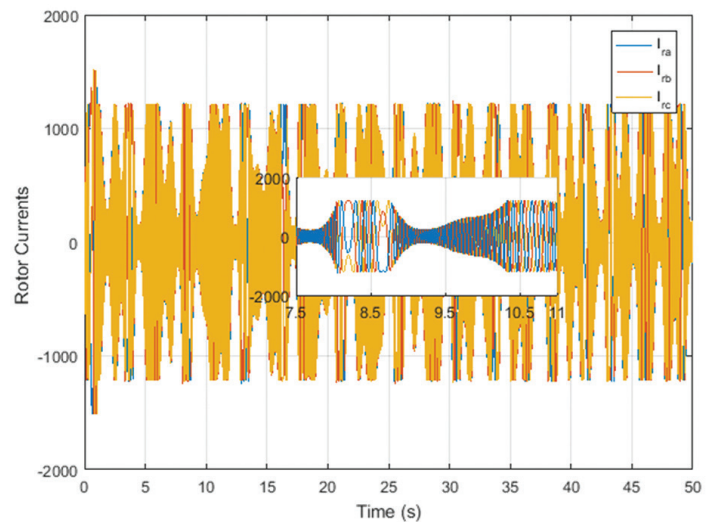

Fig. 17. The rotor's currents using the pitch control

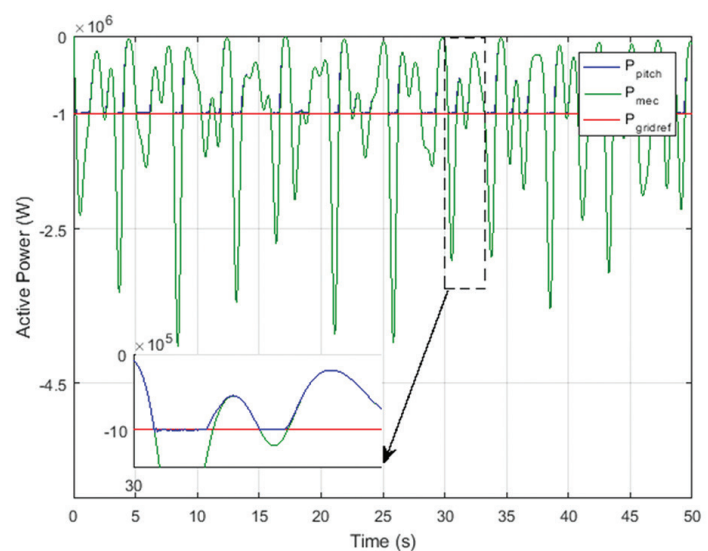

Fig. 18. The active power injected in the grid and its reference using the pitch control

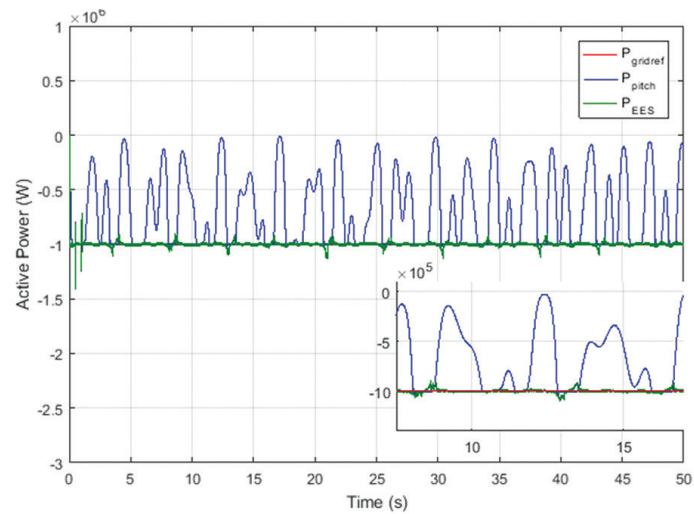

Fig. 19. The produced power injected in the grid

\section{CONCLUSION}

The purpose of this study is to smooth the produced power of the WECS, so that when injected into the grid it's more stable for the wind fluctuations. The work done in this paper consists of making a comparison between two power smoothing techniques, which are the ESS and the pitch control. First a modelling of all the parts of the conversion chain was made. Then, in order to smooth the injected power into the grid, the first method consisted of the use of a second DFIG associated with a flywheel for the storage device. There- 
fore, in the case of excess power, it is stored, recovered in the reverse case. As a control technique of the flywheel side converter, the sliding mode was used, when the second technique is the pitch control, which consists of orienting the blades' angle $\beta$ according to the power's reference. The simulation results showed that the use an ESS gives a smoother power but with peaks of rotor and stator currents, whereas in pitch control, the rotor and stator currents are limited but the injected power is not smooth enough. Otherwise, if we try to smooth the power, the use of an ESS and resizing the converters' components withstanding the peaks of the currents is needed, however the use of the second solution limits the currents but is not efficient for the power smoothing.

\section{APPENDIX}

\section{DFIG's Parameter}

$P_{n}=300 K w, f=50 \mathrm{~Hz}, R_{s}=8.9 \mathrm{~m} \Omega$ resistor, $R_{r}, 13.7 \mathrm{~m} \Omega$, $L_{s}^{n}=12.9 \mathrm{mH}, L_{r}=12.7 \mathrm{mH}, L_{m}=M=12.672 \mathrm{mH}, \sigma=0.0198$, $P=2$

\section{Filter and grid parameters}

$L=0.005 \mathrm{H}, R=0.25 \Omega, C=4400 \mu \mathrm{F}$

\section{The wind-swept turbine surface's expression:} $S=\pi R_{T}^{2}$

\section{The Aerodynamic coefficient's expression:}

$$
\begin{gathered}
\boldsymbol{C}_{\boldsymbol{p}}(\boldsymbol{\lambda}, \boldsymbol{\beta})=0.5176\left(\frac{116}{\lambda_{i}}-0.4 \beta-5\right) e^{\frac{-21}{\lambda_{i}}}+0.0068 \lambda \\
\text { Where }\left\{\begin{array}{c}
\lambda_{i}=\left(\frac{1}{\lambda+0.08 \beta}-\frac{0.035}{\beta^{3}+1}\right)^{-1} \\
\lambda=\frac{\Omega_{T} R_{T}}{V}
\end{array}\right.
\end{gathered}
$$

\section{The total inertia's expression:}

$J=\left(J_{\text {Turbine }} / G^{2}\right)+J_{\text {generator }}$

The viscous friction torque's expression:

$T_{v i s}=f \Omega_{m e c}$

\section{NOMENCLATURE}

$\Omega_{T}$ :Turbine speed.

$\mathrm{v}$ : the wind profil.

$\Omega_{\text {mec }}$ :Mecanic speed.

$T_{T}$ : Turbine torque.

$T_{\text {mec }}$ : Mecanic torque.

$\rho$ : Air density;

$S$ :Wind-swept turbine surface.

$C_{p}(\beta, \lambda)$ : Aerodynamic efficiency of the turbine often referred to as a power factor.

$J:$ The total inertia
$T_{v i s}$ :The viscous friction torque.

$J_{E S S}:$ The ESS inertia.

$V s d, V s q$ : the dq axis stator voltages.

Isd, Isq : the dq axis stator current.

$\varphi s d, \varphi s q$ : the Stator $d$ and $q$ axis fluxes.

Vrd, $V r q$ : the dq axis rotor voltages.

Ird, Irq : the dq axis rotor current.

$\varphi r d, \varphi r q$ : the rotor $\mathrm{d}$ and $\mathrm{q}$ axis fluxes.

$R s, R r$ : stator and rotor resistances.

$L s, L r$ : stator and rotor inductance.

M: Mutuel inductance.

$\omega s, \omega r$ : the supply and rotor angular frequency.

$V_{a, b, c}:$ are the single voltages from the converter.

$U d c, E$ : is the $\mathrm{DC}$ voltage that comes from the DC link.

$V_{t 1,2,3}$ are the three-phase system of the source (the grid).

$I_{t 1,2,3}$ : are the line currents coming from the source.

$I_{G S C^{\prime}} I_{R S C^{\prime}} I_{F S C}$ : are respectively the current at the converter outputs on the grid side, rotor side and the flywheel side converter.

$P, Q$ : active and reactive power.

$P_{\text {grid }}:$ The grid's active power.

$P_{D F I G}$ : the DFIG's active power.

$P_{E S S}:$ The active power of the energy storage system.

$S_{1,2,3}$ : the PWM's commands.

\section{REFERENCES}

[1] H. Elaimani, A. Essadki, N. Elmouhi, R. Chakib, "Comparative Study of the Grid Side Converter's Control during a Voltage Dip", Journal of Energy, Vol. 2020, 2020, pp. 1-11.

[2] L. Jerbi, L. Krichen, A. Ouali, "A fuzzy logic supervisor for active and reactive power control of a variable speed wind energy conversion system associated to a flywheel storage system", Electric Power Systems Research, Vol. 79, No. 6, 2009, pp. 919-925.

[3] M. Nadour, A. Essadki, T. Nasser, M. Fdaili, “Robust coordinated control using backstepping of flywheel energy storage system and DFIG for power smoothing in wind power plants", International Journal of Power Electronics and Drive Systems, Vol. 10, No. 2, 2019, pp. 1110-1122. 
[4] S. Ghosh and S. Kamalasadan, "An integrated dynamic modeling and adaptive controller approach for flywheel augmented DFIG based wind system", IEEE Transactions on Power Systems, Vol. 32, No. 3, 2017, pp. 2161-2171.

[5] S. A. Belfedhal, E. M. Berkouk, Y. Meslem, Y. Soufi, "Modeling and control of wind power conversion system with a flywheel energy storage system and compensation of reactive power", International Journal of Renewable Energy Research, Vol. 2, No. 3, 2012, pp. 528-534.

[6] F. Díaz-González, A. Sumper, O. Gomis-Bellmunt, F. D. Bianchi, "Energy management of flywheel-based energy storage device for wind power smoothing", Applied Energy, Vol. 110, 2013, pp. 207-219.

[7] X. Luo, J. Wang, M. Dooner, J. Clarke, "Overview of current development in electrical energy storage technologies and the application potential in power system operation", Applied Energy, Vol. 137, 2015, pp. 511-536.

[8] G.-O. Cimuca, "Système inertiel de stockage d"énergie associé aux générateurs éoliens", 2005.

[9] R. Riyadh, "Contrôle des puissances générées par un système éolien à vitesse variable basé sur une machine asynchrone double alimentée", 2016.

[10] R. Chakib, "Commande avancée d ' une éolienne à base de la MADA en vue de sa participation aux services système : réglage de fréquence, réglage de tension et tenue aux creux de tension", 2017.

[11] M. Smaili, "Par modélisation et commande d'un aérogénérateur à machine asynchrone à double alimentation en vue de simulation des problèmes de cogénération", 2013.

[12] H. Elaimani, A. Essadki, N. Elmouhi, R. Chakib, "Comparative Study of the Grid Side Converter's Control during a Voltage Dip", Journal of Energy, Vol. 2020, 2020, pp. 1-11.

[13] R. Chakib, A. Essadki, M. Cherkaoui, "Active Disturbance Rejection Control for Wind System Based On a DFIG", International Journal of Electrical and Computer Engineering, Vol. 8, No. 8, 2014, pp. 1249-1258.

[14] T. Ghennam, "Supervision d'une ferme éolienne pour son intégration dans la gestion d'un ré- seau électrique, Apports des convertisseus multi niveaux au réglage des éoliennes à base de machine asynchrone double alimentation", Vol. 072, 2011, pp. 1-19.

[15] Y. Djeriri, "Commande directe du couple et des puissances d 'une MADA associée à un système éolien par les techniques de l'intelligence artificielle", 2015.

[16] K. Belgacem, A. Mezouar, A. Massoum, "Sliding Mode Control of a Doubly-fed Induction Generator for Wind Energy Conversion", International Journal of Scientific \& Engineering Research, Vol. 2013, No. 1, 2013, pp. 30-36.

[17] B. Beltran, "High-Order Sliding Mode Control of a DFIG-Based Wind Turbine for Power Maximization and Grid Fault Tolerance", Proceedings of the IEEE International Electric Machines and Drives Conference, Miami, FL, USA, 3-6 May 2009, pp. 183-189.

[18] M. El azzaoui, H. Mahmoudi, K. Boudaraia, C. Eddahmani, "FPGA Implementation of Super Twisting Sliding Mode Control of the Doubly Fed Induction Generator", Proceedings of the $14^{\text {th }}$ International Multi-Conference on Systems, Signals \& Devices, Marrakech, Morocco, 28-31 March 2017.

[19] H. Elaimani, A. Essadki, "The study of the PI controler and the sliding mode of DFIG used in a WECS", Proceedings of the International Renewable and Sustainable Energy Conference, Tangier, Morocco, 4-7 December 2017.

[20] H. Elaimani, A. Essadki, N. Elmouhi, R. Chakib, "The Modified Sliding Mode Control of a Doubly Fed Induction Generator for Wind Energy Conversion During a Voltage Dip", Proceedings of the International Conference on Wireless Technologies, Embedded and Intelligent Systems, Fez, Morocco, 3-4 April 2019.

[21] L. Jerbi, L. Krichen, A. Ouali, "A fuzzy logic supervisor for active and reactive power control of a variable speed wind energy conversion system associated to a flywheel storage system", Electric Power Systems Research, Vol. 79, No. 6, 2009, pp. 919-925.

[22] X. Luo, J. Wang, M. Dooner, J. Clarke, "Overview of current development in electrical energy storage technologies and the application potential in power system operation", Applied Energy, Vol. 137, 2015, pp. 511-536. 
[23] M. Nadour, A. Essadki, T. Nasser, M. Fdaili, “Robust coordinated control using backstepping of flywheel energy storage system and DFIG for power smoothing in wind power plants", International Journal of Power Electronics and Drive Systems, Vol. 10, No. 2, 2019, pp. 1110-1122.

[24] S. Ghosh and S. Kamalasadan, "An integrated dynamic modeling and adaptive controller approach for flywheel augmented DFIG based wind system", IEEE Transactions on Power Systems, Vol. 32 , No. 3, 2017, pp. 2161-2171.

[25] S. A. Belfedhal, E. M. Berkouk, Y. Meslem, Y. Soufi, "Modeling and control of wind power conversion system with a flywheel energy storage system and compensation of reactive power", International Journal of Renewable Energy Research, Vol. 2, No. 3, 2012, pp. 528-534.

[26] F. Díaz-González, A. Sumper, O. Gomis-Bellmunt, F. D. Bianchi, “Energy management of flywheel-based energy storage device for wind power smoothing", Applied Energy, Vol. 110, 2013, pp. 207-219.

[27] G.-O. Cimuca, "Système inertiel de stockage d"énergie associé aux générateurs éoliens", 2005.
[28] B. Hamane, M. L. Doumbia, M. Bouhamida, A. Draou, H. Chaoui, M. Benghanem, “Comparative Study of PI, RST, Sliding Mode and Fuzzy Supervisory Controllers for DFIG based Wind Energy Conversion System", International Journal of Renewable Energy Research, Vol. 5, No. 4, 2015, pp. 1174-1185.

[29] S. ELAimani, "Modelisation de differentes technologies d'eoliennes integrees dans un reseau de moyenne tension", 2004.

[30] N. El Ouanjli, M. Taoussi, A. Derouich, A. Chebabhi, A. El Ghzizal, B. Boussoufi “High Performance Direct Torque Control of Doubly Fed Induction Motor using Fuzzy Logic", Gazi university journal of science, Vol. 31, No. 2, 2018, pp. 532-542.

[31] N. El Ouanjli, A. Derouich, A. El Gzizal, Y. El Mourabet, B. Bossoufi, M. Taoussi, "Contribution to the performance improvement of Doubly Fed Induction Machine functioning in motor mode by the DTC control", International Journal Power Electronics and Drive System, Vol.8, No.3, 2017, pp. 1117-1127. 